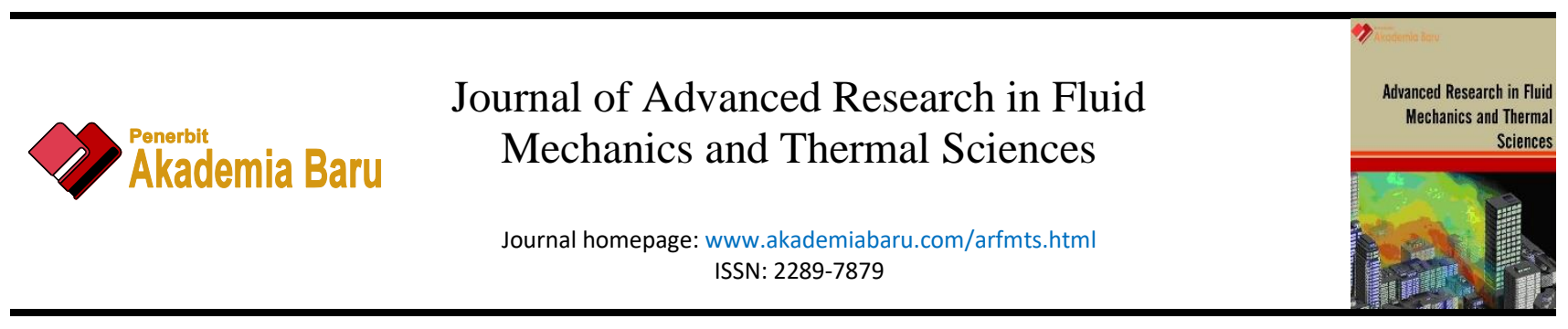

\title{
MHD Stagnation Point Flow over a Nonlinear Stretching/Shrinking Sheet in Nanofluids
}

ARTICLE INFO

\section{Article history:}

Received 24 May 2020

Received in revised form 18 September 2020

Accepted 22 September 2020

Available online 28 October 2020

\section{Keywords:}

Magnetohydrodynamic; flow of stagnation

point; nonlinear sheet of

stretching/shrinking; nanofluids; dual

solutions

\section{ABSTRACT}

In this study, an investigation of the steady 2-D magnetohydrodynamiic (MHD) flow of stagnation point past a nonlinear sheet of stretching/shrinking within of a nonuniform transverse magnetic intensity in nanofluids had been analysed. Considered material of nanoparticles such as copper $(\mathrm{Cu})$ in water base fluid with $\operatorname{Pr}=6.2$ to analyze the influence of volume fraction parameter of nanoparticles and the stretching/shrinking sheet parameter. The governing nonlinear partial differential equations (PDEs) are converted in to the nonlinear ordinary differential equations (ODEs) and use the boundary value problem solver bvp4c in Matlab program to solve numerically through the use of a similarity transformation. The impact of the parameter of the magnetic field on the coefficient of skin friction, the local number of Nusselt and the profiles of velocity and temperature are portrayed and explained physically. The analysis reveals that the magnetic field and volume fraction of nanoparticles affect the velocity and temperature. The dual solutions are achieved where for the shrinking sheet case and the solutions are non-unique, different from a stretching sheet.

\section{Introduction}

In the problem of boundary layer, the stagnation point flow phenomenon was picked up by several researchers due to several of uses in the manufacturing sector for system cooling purposes. Stagnation point flow is the continuous motion near a solid surface's stagnation district that exists in a fluid in both instances of a static or in motion body. Hiemenz [1] became the first scientist to test the steady of 2-D flow of stagnation point to a static semi-infinite surface and obtained an accurate the Navier-Stokes equation solution. Previously, several scientists had selected curiosity in the inquiry into the flow of boundary layer and heat transfer of the sheet of stretching. Crane [2] also researched

* Corresponding author.

E-mail address: norhathirah95@gmail.com

https://doi.org/10.37934/arfmts.76.3.139152 
the first problem of the flow of boundary layer through a linear sheet of stretching. Chiam [3], who is researching the flow of stagnation point past a sheet of stretching developed the works of Hiemenz [1] and Crane [2]. Thus Miklavčič and Wang [4] investigated the flow equation of similarity solution past a surface of shrinking and noticed that it relies on the outer mass suction. The heat transfer in the flow of stagnation point past a sheet of stretching over a viscoelastic fluid, respectively, was explored by Mahapatra and Gupta [5,6]. Next, for both 2-D and axisymmetric situations, the flow of stagnation point past a shrinking surface was explored by Wang [7]. For particular values of the shrinking and stretching rate ratio, the dual and unique solutions are identified.

There are many researchers who have been researching exponential and linear stretching/shrinking surfaces. Magyari and Keller [8] were the earliest to acknowledge the continuous boundary layers and heat transfer through a constant of an exponential stretching surface. Then, the study continued by Rohni et al., [9] who work into the exponential shrinking of vertical sheet with suction and the buoyancy force. Numerical findings showed that the existence of buoyancy force would make a contribution to the presence of triple solutions for a specific value of relevant parameters, while the problem has only dual solutions in the absence of the buoyancy force. Mansur et al., [10] have been using the Buongiorno model to explore the flow of stagnation point to a permeable sheet of stretching/shrinking with the effect of suction in nanofluid. They observed that when the sheet is extended, the skin friction reduces, but rises as the suction impact increases. The MHD flow of boundary layer past the flow of stagnation point of a linear surface of stretching was explored by Jat and Chaudhary [11, 12]. Within of the magnetic field, the continuous flow of stagnation point of two-dimensional in a viscous fluid is observed by Aman et al., [13] through a linear sheet of stretching/shrinking. The results show that there are dual solutions for the sheet of shrinking, while the solution for the sheet of stretching is unique.

However, the earliest researcher to analyse the flow in viscous fluid past a nonlinear sheet of stretching is Vajravelu [14]. They found that the heat flow is consistently come from the sheet of stretching to the fluid. Bachok and Ishak [15] had been investigated the similarity solutions past a nonlinearly sheet of stretching/shrinking for the stagnation point flow. This problem is solved by using shooting method and found that the solutions are non-unique for $m>1 / 3$ for a case of sheet of shrinking, and unique for a case of sheet of stretching. In addition, the rate of heat transfer for stretching sheet is larger than shrinking sheet for the stable solution. Jat and Neemawat [16] also study the same problem but with the effect of MHD. A similar study for a nonlinear sheet of stretching had been analysed by Rana and Bhargava [17]. Matin et al., [18] had been study the flow of mixed convective in nanofluid past a sheet of stretching with the effect of MHD.

The objective of the research is to analysed the impact of magnetohydrodynamic (MHD) in a nanofluid on the flow of stagnation point past a nonlinear sheet of stretching/shrinking which consider the Tiwari and Das [19] model. Consideration is given to the influence of parameter of magnetic field and volume fraction of nanoparticles on the skin friction and temperature. A bvp4c solver in Matlab program is used numerically to solve the governing equations.

\section{Methodology}

Consider a flow of stagnation point of steady, incompressible, laminar, 2-D MHD past a nonlinear sheet of stretching/shrinking in a water-based nanofluid involving $\mathrm{Cu}$ as a type of nanoparticles. A non-uniform transverse magnetic intensity $B=B_{0} x^{(n-1) / 2}$ is applied perpendicular to the sheet, where $B_{0}$ is an uniform magnetic intensity. The generated magnetic field is ignored because of the movement of an electrically conducting field. It is concluded that the sheet's velocity is $U_{w}(x)=a x^{n}$ and the velocity outside the boundary layer is $U_{s}(x)=b x^{n}$ where $a$ is the stretching/shrinking rate, 
$b>0$ is a constant denotes the strength of the flow of stagnation and $n$ is the stretching index. The simplified 2-D MHD equations of governing are

$\frac{\partial u}{\partial x}+\frac{\partial v}{\partial x}=0$

$u \frac{\partial u}{\partial x}+v \frac{\partial u}{\partial y}=U_{s} \frac{d U_{s}}{d x}+\frac{\mu_{n f}}{\rho_{n f}} \frac{\partial^{2} u}{\partial y^{2}}+\frac{\sigma B_{0}^{2}}{\rho_{f}}\left(U_{s}-u\right)$,

$u \frac{\partial T}{\partial x}+v \frac{\partial T}{\partial y}=\alpha_{n f} \frac{\partial^{2} T}{\partial y^{2}}$

corresponding to boundary conditions

$u=U_{w}(x), v=0, T=T_{w}(x)$ at $y=0$,

$u \rightarrow U_{s}(x), T \rightarrow T_{\infty}$ as $y \rightarrow \infty$,

which are $u$ is the $x$ - axes and $v$ is $y$ - axes along the velocity components and $\sigma$ is the fluid's electrical conductivity. $T$ is the nanofluid's temperature, $T_{w}$ is the variable sheet temperature and $T_{\infty}$ is the free flow temperature assuming it is fixed, which are defined as follows (Oztop and Abu Nada [20])

$$
\begin{aligned}
& \alpha_{n f}=\frac{k_{n f}}{\left(\rho C_{p}\right)_{n f}}, \rho_{n f}=(1-\varphi) \rho_{f}+\varphi \rho_{s}, \mu_{n f}=\frac{\mu_{f}}{(1-\varphi)^{2.5}} \\
& \left(\rho C_{p}\right)_{n f}=(1-\varphi)\left(\rho C_{p}\right)_{f}+\varphi\left(\rho C_{p}\right)_{s}, \frac{k_{n f}}{k_{f}}=\frac{\left(k_{s}+2 k_{f}\right)-2 \varphi\left(k_{f}-k_{s}\right)}{\left(k_{s}+2 k_{f}\right)+\varphi\left(k_{f}-k_{s}\right)}
\end{aligned}
$$

Here, $\varphi$ is the nanofluid's nanoparticle volume fraction parameter, $\rho_{n f}$ is the nanofluid's density, $\alpha_{n f}$ is the nanofluid's thermal diffusivity, $k_{n f}$ is the fluid fraction's thermal conductivity, $k_{s}$ is the nanoparticle volume fraction's thermal conductivity, $\rho_{f}$ is the solid fraction's reference density, $\mu_{n f}$ is the fluid fraction's viscosity and $\left(\rho C_{p}\right)_{n f}$ is the nanofluids' heat capacitance, where $C_{p}$ at constant pressure is the specific heat. Brinkman [21] computed the nanofluid's viscosity of $\mu_{n f}$ as the base fluid viscosity of $\mu_{f}$ involving diluted suspension of good spherical particles.

The similarity transformation is used in order to gain a similar solution for the equation of momentum and energy Eq. (1) - (3)

$\eta=y \sqrt{\frac{b(n+1)}{2 v_{f}}} x^{\frac{n-1}{2}}, \psi=\sqrt{\frac{2 v_{f} b}{n+1}} x^{\frac{n+1}{2}} f(\eta), \theta(\eta)=\frac{T-T_{\infty}}{T_{w}-T_{\infty}}$

which are $\eta$ is the variable of similarity and $\psi$ is the function of stream described as $u=\frac{\partial \psi}{\partial y}$ and $v=$ $-\frac{\partial \psi}{\partial x}$, which equivalently fulfilled with continuity equation, Eq. (1).

The converted ODEs are

$\frac{1}{(1-\varphi)^{2.5}\left(1-\varphi+\varphi \rho_{s} / \rho_{f}\right)} f^{\prime \prime \prime}+f f^{\prime \prime}+\frac{2 n}{n+1}\left(1-f^{\prime 2}\right)+\frac{2 M}{n+1}\left(1-f^{\prime}\right)=0$, 
$\frac{1}{\operatorname{Pr}} \frac{k_{n f} / k_{f}}{\left[1-\varphi+\varphi\left(\rho C_{p}\right)_{s} /\left(\rho C_{p}\right)_{f}\right]} \theta^{\prime \prime}+f \theta^{\prime}=0$,

corresponding to the boundary conditions (4)

$f(0)=0, \quad f^{\prime}(0)=\varepsilon, \quad \theta(0)=1$,

$f^{\prime}(\eta) \rightarrow 1, \theta(\eta) \rightarrow 0$, as $\quad \eta \rightarrow \infty$

From the equations, the primes indicate differentiation in respect of $\eta$, where $\mathrm{Pr}=v_{f} / \alpha_{f}$ is the number of Prandtl, $M=\sigma B_{0}^{2} / b \rho_{f}\left(x^{1-n}\right)$ is the magnetic parameter and $\varepsilon=a / b$ is the stretching/shrinking parameter which are $\varepsilon>0$ is for stretching sheet case and $\varepsilon<0$ is for shrinking sheet case.

The coefficient of skin friction $C_{f}$ and the local Nusselt number $N u_{x}$ in the physical quantities of interest are

$C_{f}=\frac{\tau_{w}}{\rho_{f} U_{s}^{2}}, N u_{x}=\frac{x q_{w}}{k_{f}\left(T_{w}-T_{\infty}\right)}$

which are the surface shear stress $\tau_{w}$ and the suface heat flux $q_{w}$ are defined as

$\tau_{w}=\mu_{n f}\left(\frac{\partial u}{\partial y}\right)_{y=0}, q_{w}=-k_{n f}\left(\frac{\partial T}{\partial y}\right)_{y=0}$

Applying the similarity variables (7), we obtained

$C_{f} R e_{x}^{1 / 2}=\frac{1}{(1-\varphi)^{2.5}} \sqrt{\frac{n+1}{2}} f^{\prime \prime}(0)$,

$N u_{x} / R e_{x}^{1 / 2}=-\frac{k_{n f}}{k_{f}} \sqrt{\frac{n+1}{2}} \theta^{\prime}(0)$

where $R e_{x}=U_{s} x / v_{f}$.

\section{Results}

The ODEs equations Eq. (8) - (10) are nonlinear and coupled, and therefore their accurate analytical solutions are impossible. These can be solved numerically using Matlab's bvp4c solver because of its usefulness in finding a solution for boundary value problems that are far more complicated than initial value problems of various parameter values such as $M, \varphi$ and $\varepsilon$. By choosing various initial guesses for the lost values for $f^{\prime \prime}(0)$ and $\theta^{\prime}(0)$ the dual solutions were obtained. The guess must meet the boundary conditions (10) asymptotically, while maintaining the solution's behavior. For copper (Cu) as the working fluids, an analysis of the influence of $\varphi, \operatorname{Pr}$ and $M$ and water as the fluid base that works are consider. The $\operatorname{Pr}$ is considered $\operatorname{Pr}=6.2$ and $\varphi$ is assumed from 0 to 0.2 $(0 \leq \varphi \leq 0.2)$, where $\varphi=0$ refers to the regular fluid. Table 1 lists the thermophysical characteristics of the base fluid and nanoparticles. Table 2 and Table 3 show a comparison of the numerical values of $R e_{x}^{1 / 2} C_{f}$ and $R e_{x}^{-1 / 2} N u_{x}$ for $\mathrm{Cu}$-water between the past work in Rahman et al., 
[22] and the current work showing a favorable agreement. With various values of $\varepsilon, M$ and $\varphi$, numerical computations were conducted.

Table 1

Properties of thermophysical of base flid and nanoparticles [20]

\begin{tabular}{lll}
\hline Properties of physical & Fluid phase (water) & $\mathrm{Cu}$ \\
\hline$C_{p}(\mathrm{~J} / \mathrm{kgK})$ & 4179 & 385 \\
$\rho\left(\mathrm{kg} / \mathrm{m}^{3}\right)$ & 997.1 & 8933 \\
$k(\mathrm{~W} / \mathrm{mK})$ & 0.613 & 400 \\
\hline
\end{tabular}

\section{Table 2}

\begin{tabular}{|c|c|c|c|c|}
\hline \multirow[t]{2}{*}{$M$} & \multirow[t]{2}{*}{$\varepsilon$} & \multirow[t]{2}{*}{$\varphi$} & Rahman et al., [22] & Current results \\
\hline & & & \multicolumn{2}{|l|}{ Cu-water } \\
\hline \multirow{9}{*}{0} & -0.5 & 0 & 2.1182 & 2.1182 \\
\hline & & 0.1 & 3.2382 & 3.2382 \\
\hline & & 0.2 & 4.5071 & 4.5071 \\
\hline & 0 & 0 & 1.6872 & 1.6872 \\
\hline & & 0.1 & 2.5793 & 2.5793 \\
\hline & & 0.2 & 3.5901 & 3.5901 \\
\hline & 0.5 & 0 & 0.9604 & 0.9845 \\
\hline & & 0.1 & 1.4682 & 1.5051 \\
\hline & & 0.2 & 2.0436 & 2.0950 \\
\hline \multirow{9}{*}{0.1} & -0.5 & 0 & 2.1078 & 2.1708 \\
\hline & & 0.1 & 3.3186 & 3.3186 \\
\hline & & 0.2 & 4.6191 & 4.6191 \\
\hline & 0 & 0 & 1.7165 & 1.7165 \\
\hline & & 0.1 & 2.6241 & 2.6241 \\
\hline & & 0.2 & 3.6524 & 3.6524 \\
\hline & 0.5 & 0 & 0.9733 & 0.9971 \\
\hline & & 0.1 & 1.4879 & 1.5243 \\
\hline & & 0.2 & 2.0710 & 2.1216 \\
\hline \multirow{9}{*}{0.2} & -0.5 & 0 & 2.2222 & 2.2222 \\
\hline & & 0.1 & 3.3971 & 3.3971 \\
\hline & & 0.2 & 4.7284 & 4.7284 \\
\hline & 0 & 0 & 1.7453 & 1.7453 \\
\hline & & 0.1 & 2.6681 & 2.6681 \\
\hline & & 0.2 & 3.7137 & 3.7137 \\
\hline & 0.5 & 0 & 0.9860 & 1.0094 \\
\hline & & 0.1 & 1.5073 & 1.5432 \\
\hline & & 0.2 & 2.0980 & 2.1478 \\
\hline
\end{tabular}




\begin{tabular}{|c|c|c|c|c|}
\hline \multirow[t]{2}{*}{$M$} & \multirow[t]{2}{*}{$\varepsilon$} & \multirow[t]{2}{*}{$\varphi$} & Rahman et al., [22] & Currents results \\
\hline & & & \multicolumn{2}{|l|}{ Cu-water } \\
\hline \multirow{9}{*}{0} & \multirow[t]{3}{*}{-0.5} & 0 & 0.6870 & 0.6870 \\
\hline & & 0.1 & 1.1432 & 1.1432 \\
\hline & & 0.2 & 1.5185 & 1.5185 \\
\hline & \multirow[t]{3}{*}{0} & 0 & 1.7148 & 1.7148 \\
\hline & & 0.1 & 2.1358 & 2.1358 \\
\hline & & 0.2 & 2.5400 & 2.5400 \\
\hline & \multirow[t]{3}{*}{0.5} & 0 & 1.4874 & 3.0095 \\
\hline & & 0.1 & 2.9149 & 3.5235 \\
\hline & & 0.2 & 3.3565 & 4.0560 \\
\hline \multirow{9}{*}{0.1} & \multirow[t]{3}{*}{-0.5} & 0 & 0.7079 & 0.7079 \\
\hline & & 0.1 & 1.1649 & 1.1649 \\
\hline & & 0.2 & 1.5419 & 1.5419 \\
\hline & \multirow[t]{3}{*}{0} & 0 & 1.7220 & 1.7220 \\
\hline & & 0.1 & 2.1442 & 2.1442 \\
\hline & & 0.2 & 2.5494 & 2.5494 \\
\hline & \multirow[t]{3}{*}{0.5} & 0 & 2.4897 & 3.0119 \\
\hline & & 0.1 & 2.9177 & 3.5266 \\
\hline & & 0.2 & 3.3597 & 4.0596 \\
\hline \multirow{9}{*}{0.2} & \multirow[t]{3}{*}{-0.5} & 0 & 0.7279 & 0.7279 \\
\hline & & 0.1 & 1.1857 & 1.1857 \\
\hline & & 0.2 & 1.5642 & 1.5642 \\
\hline & \multirow[t]{3}{*}{0} & 0 & 1.7291 & 1.7291 \\
\hline & & 0.1 & 2.1524 & 2.1524 \\
\hline & & 0.2 & 2.5586 & 2.5586 \\
\hline & \multirow[t]{3}{*}{0.5} & 0 & 2.4919 & 3.0143 \\
\hline & & 0.1 & 2.9205 & 3.5296 \\
\hline & & 0.2 & 3.3629 & 4.0632 \\
\hline
\end{tabular}

Figure 1 - 6 shown the variation of $f^{\prime \prime}(0)$ and $\theta^{\prime}(0)$ for certain magnetic field parameter value $M$, volume fraction of nanoparticles $\varphi$ and the stretching index $n$ towards $\varepsilon$ for $\mathrm{Cu}$ in water base fluid. These figures observed that the solution is unique at the region $\varepsilon \geq 1$, dual at the region $\varepsilon_{c} \leq$ $\varepsilon<-1$ and at the region $\varepsilon<\varepsilon_{c}<0$ there are no solutions, which is $\varepsilon_{c}$ is the critical value of $\varepsilon$. We can show from Figure 1 and 2, that the $M$ increase will increase the $\varepsilon_{c}$ range. Thus, for $M=0$, the range of $\varepsilon$ for which there is a similarity solution is smaller, i.e. $-1.349802 \leq \varepsilon<\infty$, while for $M=$ 0.1 and $M=0.2$, the range are $-1.397694 \leq \varepsilon<\infty$ and $-1.445707 \leq \varepsilon<\infty$, respectively. From these figures, we also can conclude that the rate of boundary layer and the rate of heat transfer increase because of an increment of the values of $M$.

Then, Figure 7 and 8 depict the variations of $C_{f} R e_{x}^{1 / 2}$ and $N u_{x} R e_{x}^{-1 / 2}$ for several values of $M$ for $\mathrm{Cu}$ in water base fluid with $\varepsilon=1.5$ and $n=2$. These figures stated that as the $M$ is increasing, the value of $C_{f} R e_{x}^{1 / 2}$ and $N u_{x} R e_{x}^{-1 / 2}$ is decreasing. In contrast, the profiles of velocity and temperature of various $M$ and $n$ are shown visually in Figure 9 - 12. These profiles prove the existing of the dual solution in the Figure 1 - 6 that satisfy the far zone boundary conditions (10) asymptotically. 


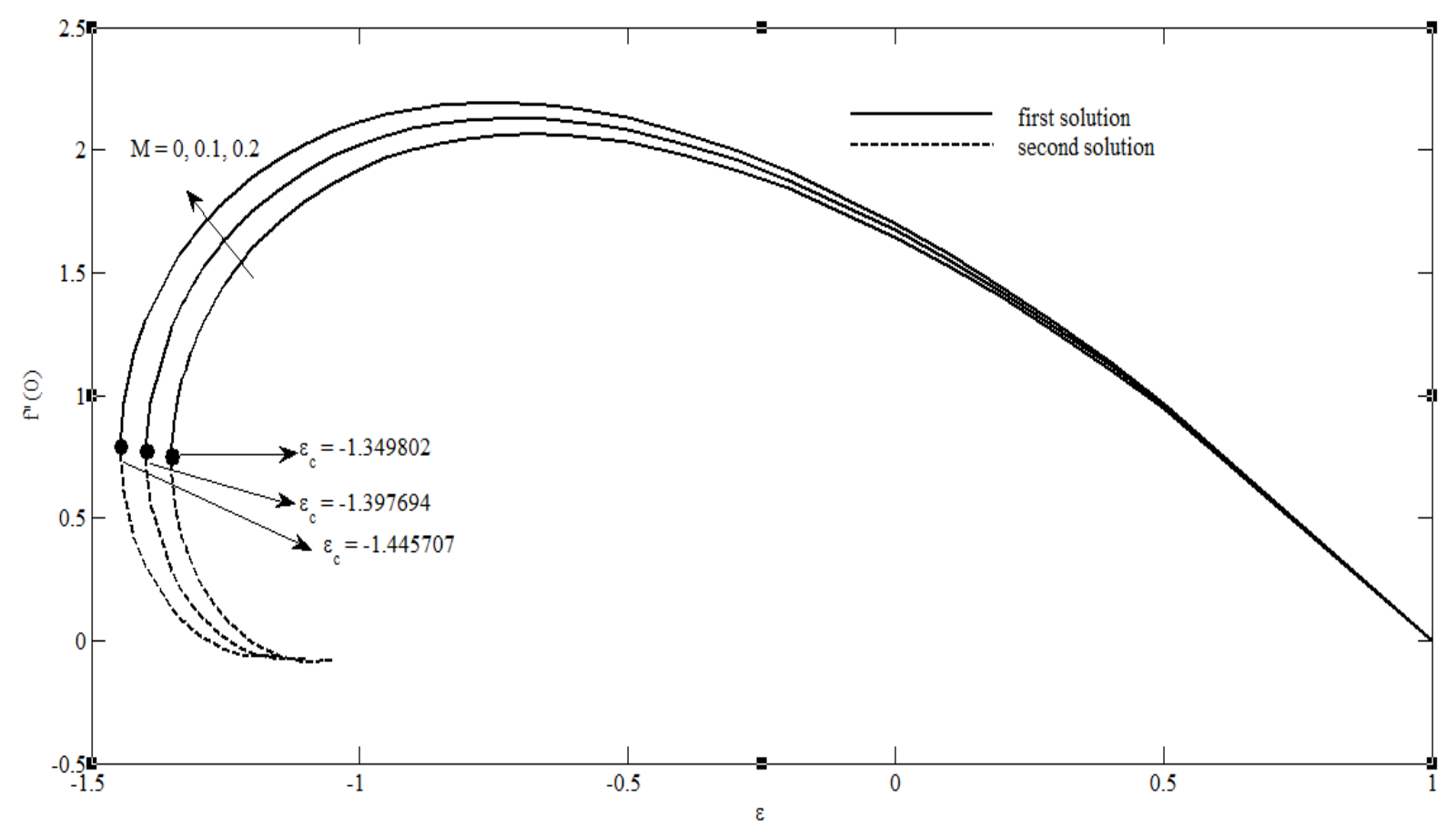

Fig. 1. $f^{\prime \prime}(0)$ with $\varepsilon$ for some values of $M$ for Cu-water, $\operatorname{Pr}=6.2, \varphi=0.1$ and $n=2$

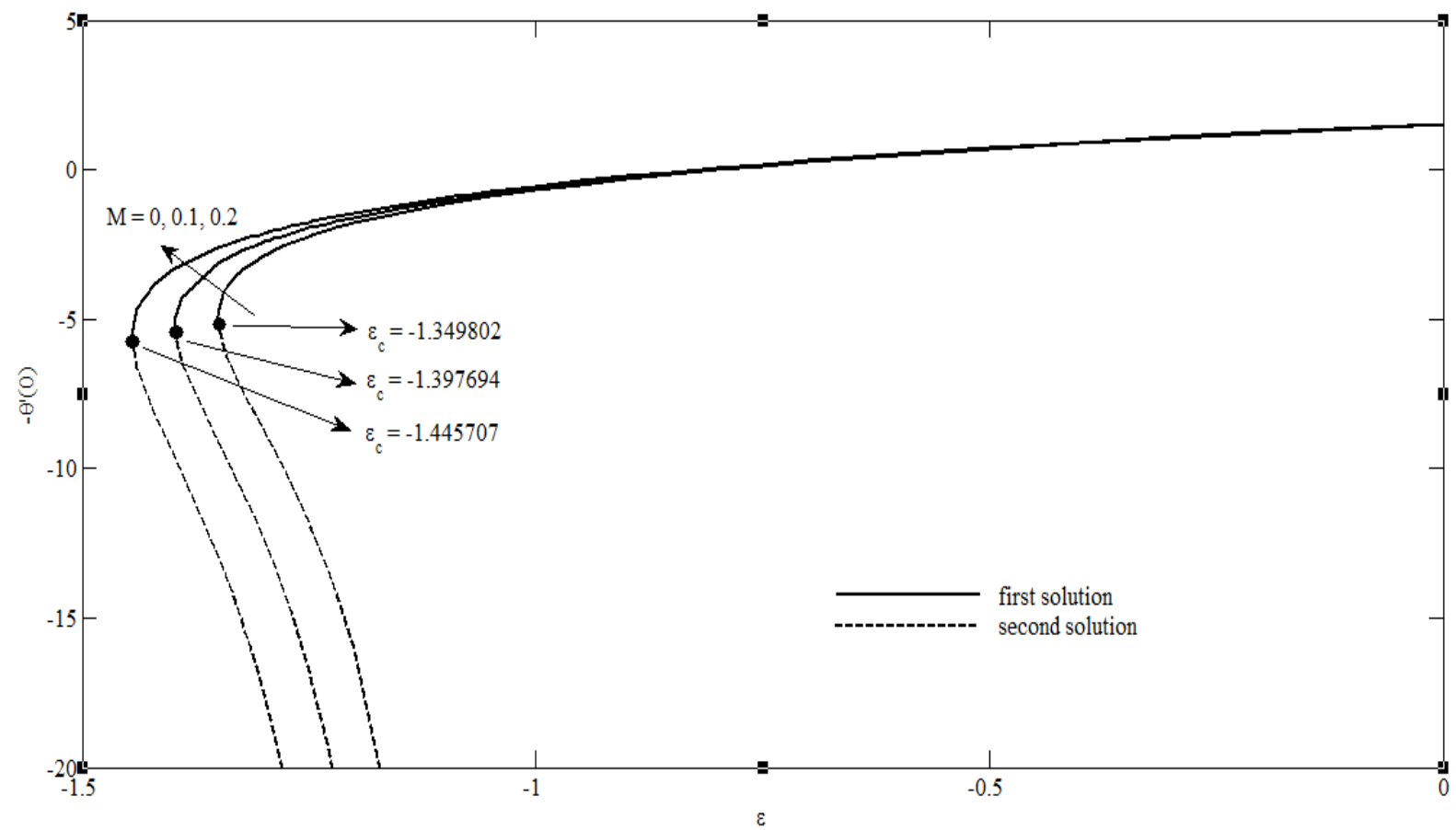

Fig. 2. $-\theta^{\prime}(0)$ with $\varepsilon$ for some values of $M$ for Cu-water, $\operatorname{Pr}=6.2, \varphi=0.1$ and $n=2$ 


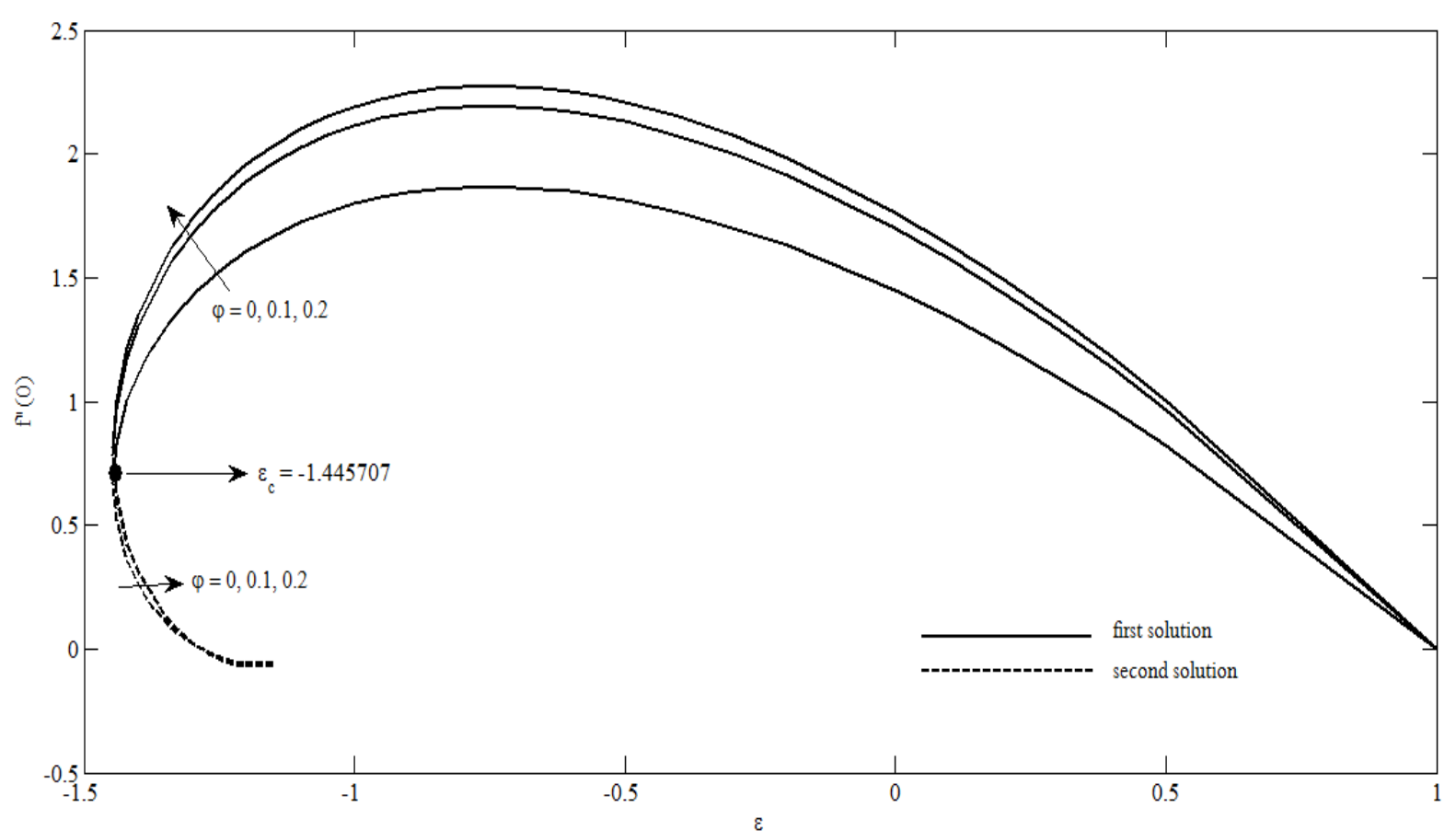

Fig. 3. $f^{\prime \prime}(0)$ with $\varepsilon$ for some values of $\varphi(0 \leq \varphi \leq 0.2)$ for Cu-water, $\operatorname{Pr}=6.2, M=0.2$ and $n=2$

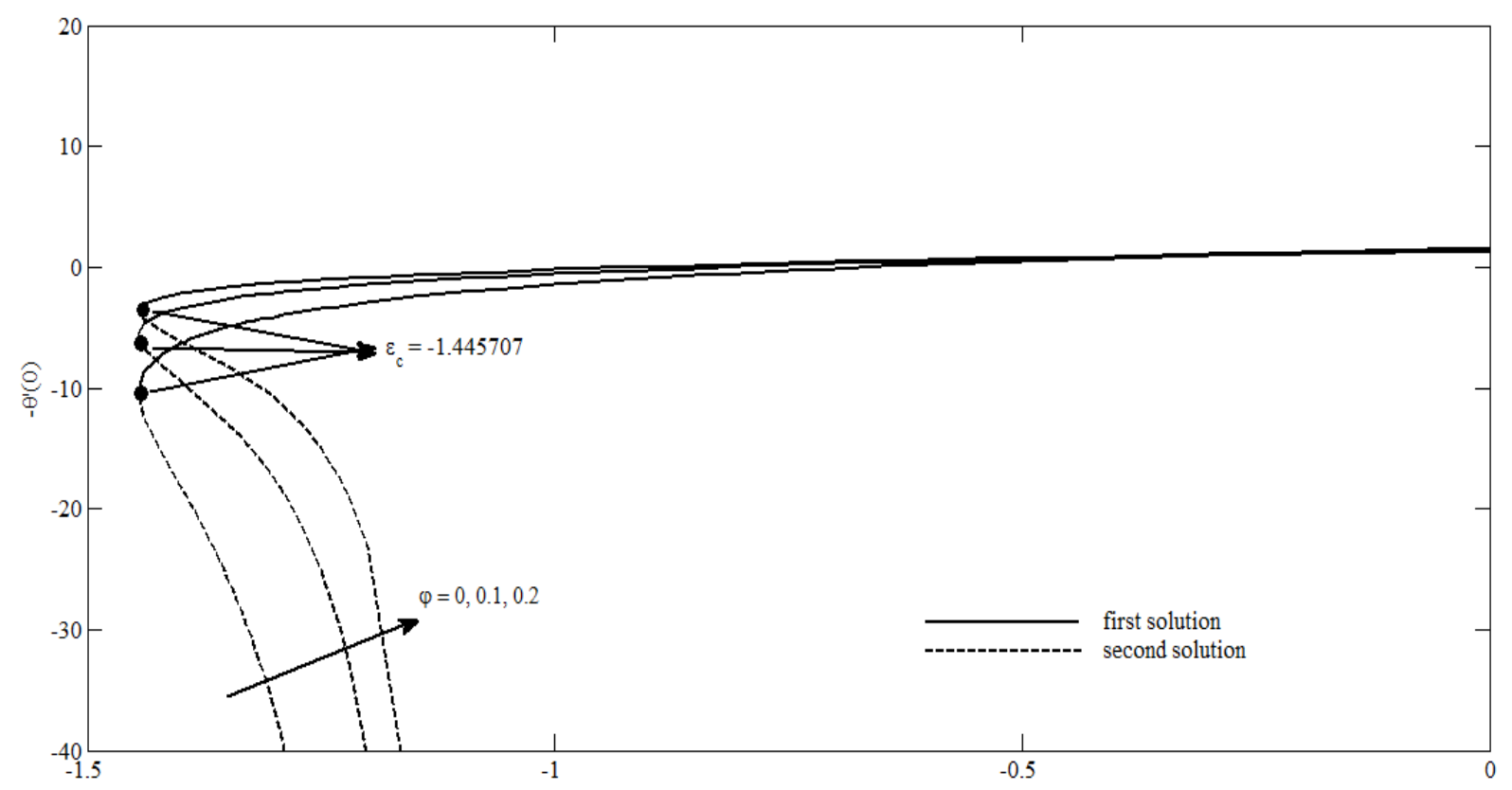

Fig. 4. $-\theta^{\prime}(0)$ with $\varepsilon$ for some values of $\varphi(0 \leq \varphi \leq 0.2)$ for Cu-water, $\operatorname{Pr}=6.2, M=0.2$ and $n=2$ 


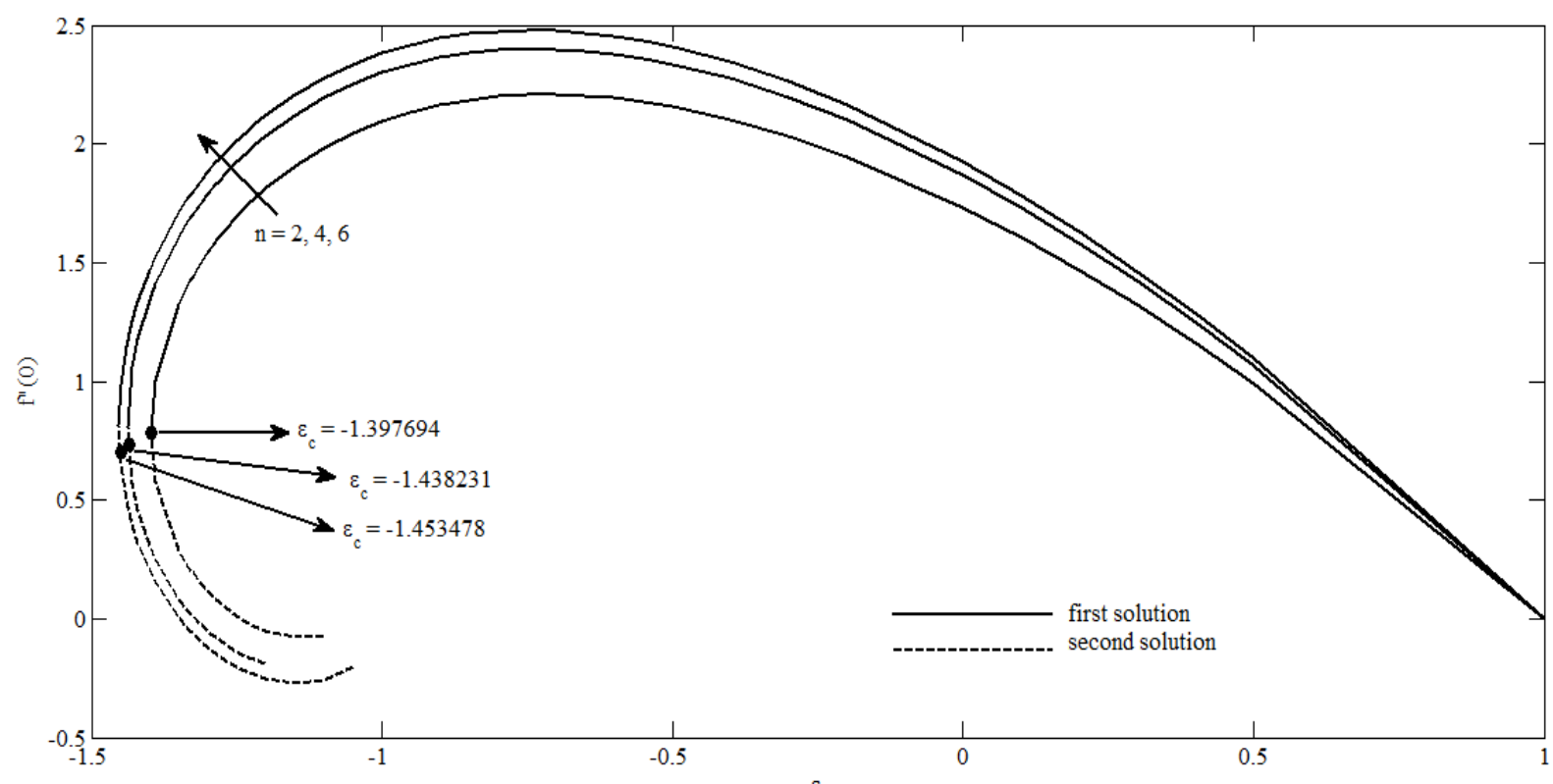

Fig. 5. $f^{\prime \prime}(0)$ with $\varepsilon$ for some values of $n$ for $C u$-water, $\operatorname{Pr}=6.2, M=0.1$ and $\varphi=0.2$

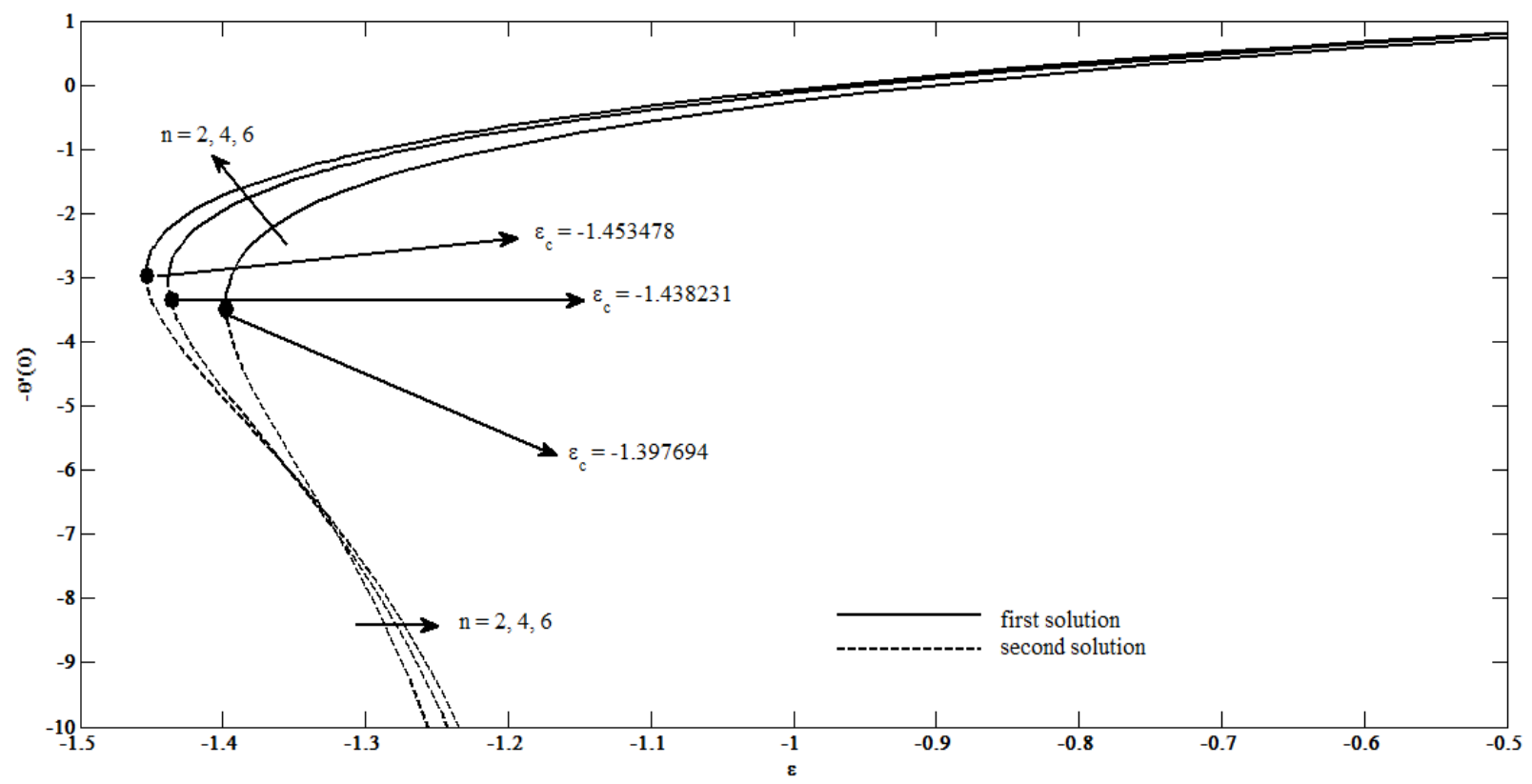

Fig. 6. $-\theta^{\prime}(0)$ with $\varepsilon$ for some values of $n$ for Cu-water, $\operatorname{Pr}=6.2, M=0.1$ and $\varphi=0.2$ 


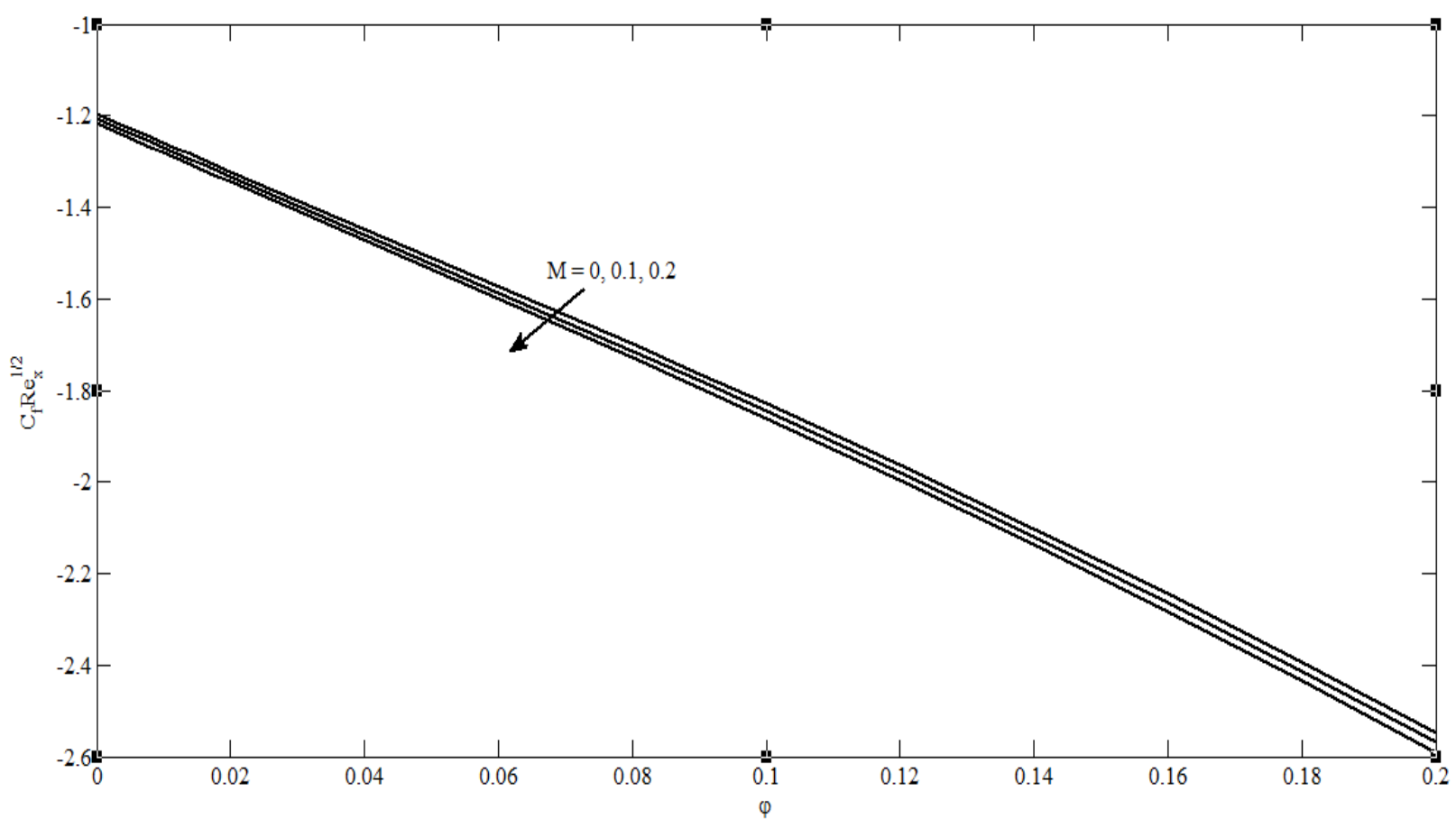

Fig. 7. $C_{f} R e_{x}^{1 / 2}$ with $\varepsilon$ for different magnetic field $M$ for $C u$-water, $\operatorname{Pr}=6.2, \varepsilon=1.5$ and $n=2$

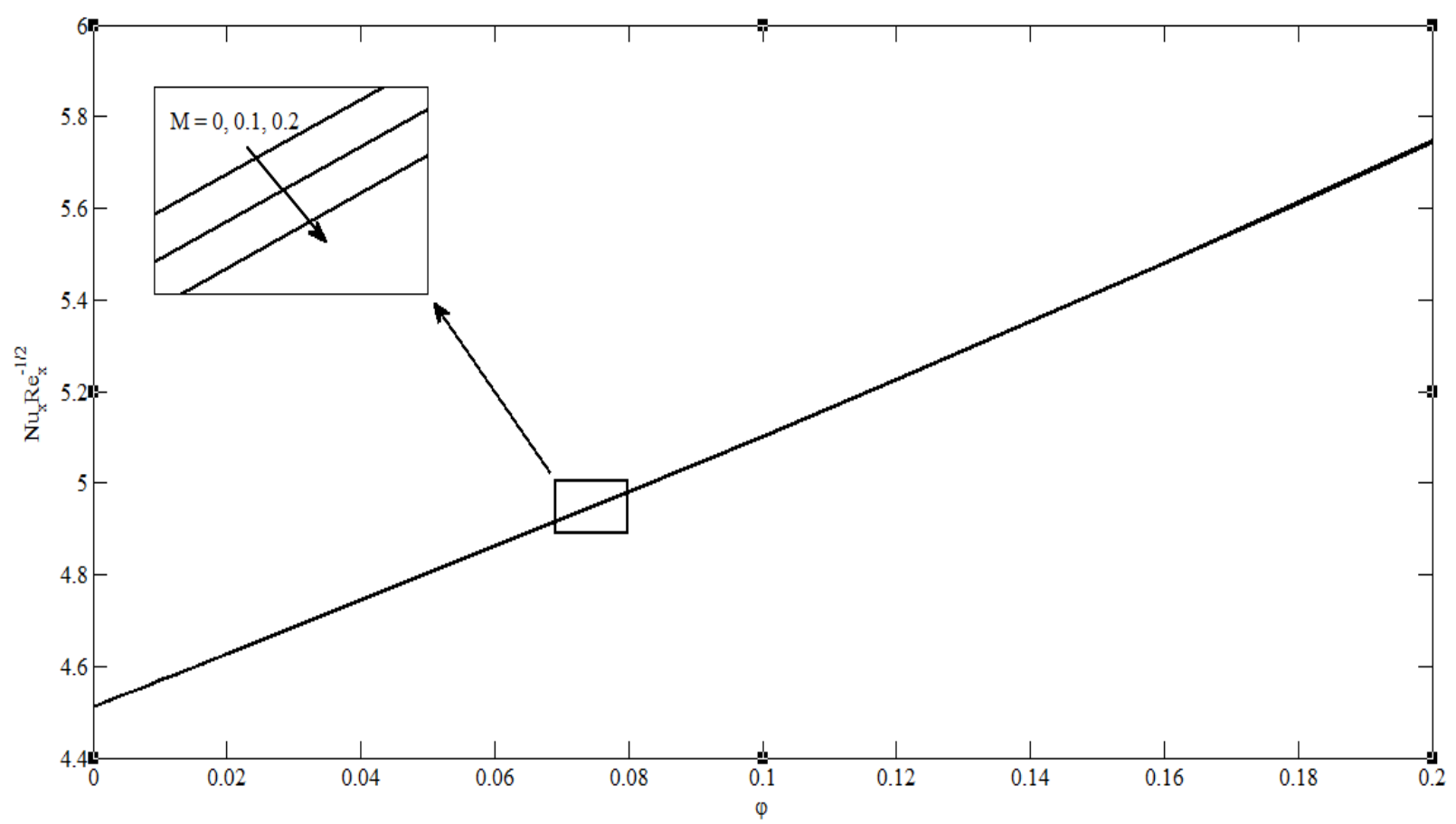

Fig. 8. $N u_{x} R e_{x}^{-1 / 2}$ with $\varepsilon$ for different magnetic field $M$ for $\mathrm{Cu}$-water, $\operatorname{Pr}=6.2, \varepsilon=1.5$ and $n=2$ 


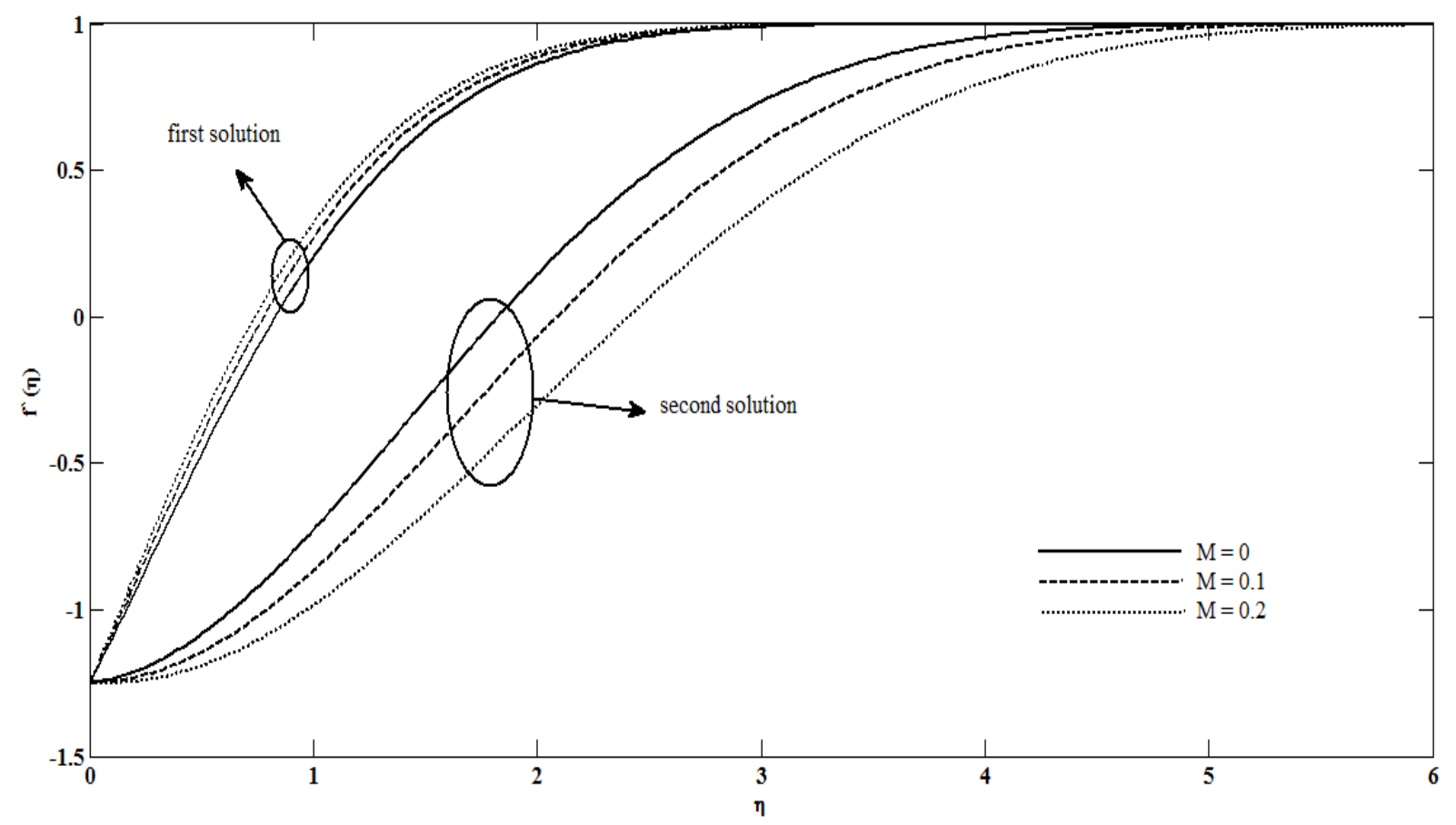

Fig. 9. Velocity profiles for different values of $M$ for Cu-water, $\varphi=0.1, \varepsilon=-1.25, n=2$ and $\operatorname{Pr}=$ 6.2

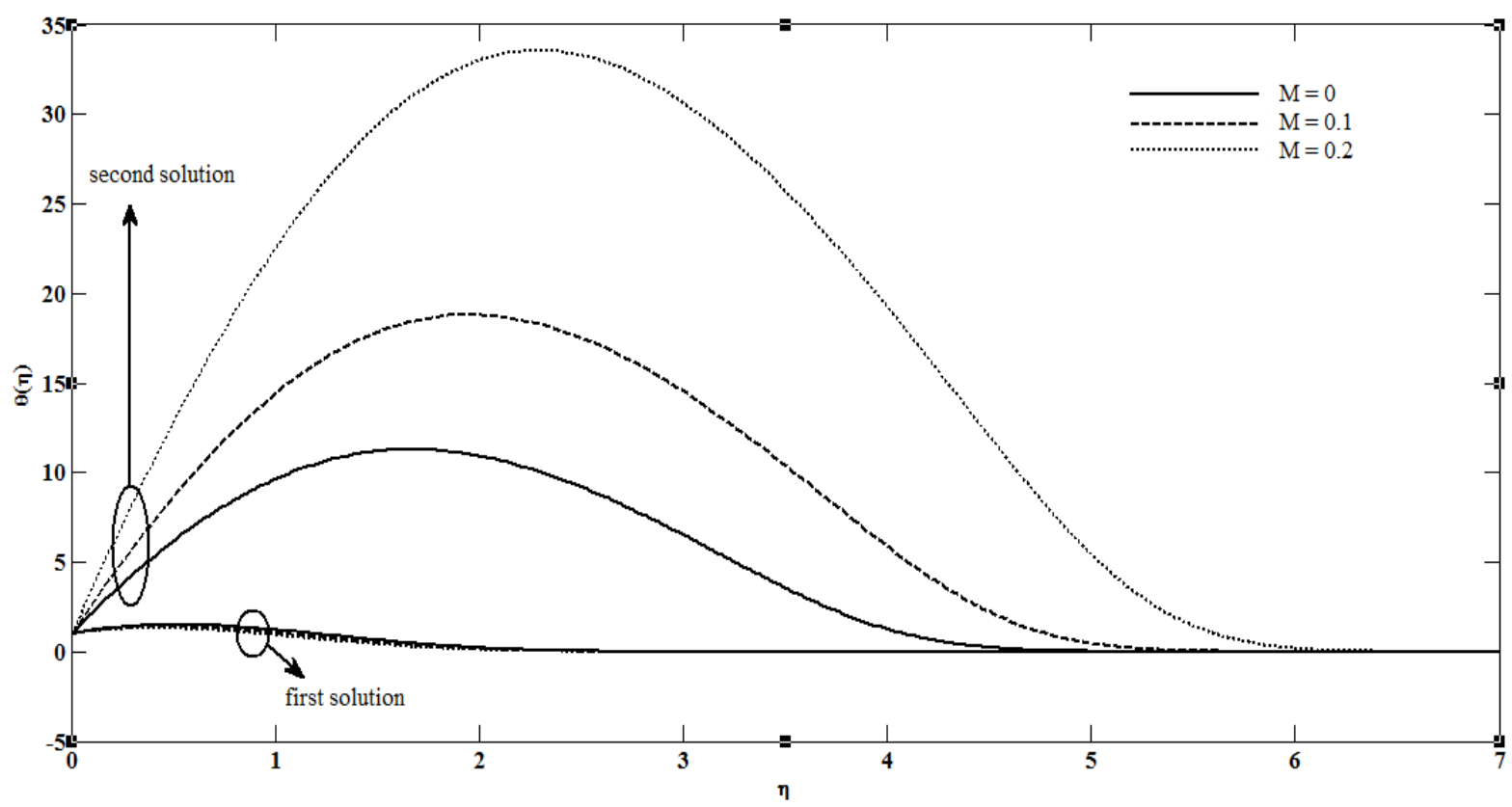

Fig. 10. Temperature profiles for different values of $M$ for Cu-water, $\varphi=0.1, \varepsilon=-1.25, n=2$ and $\operatorname{Pr}=6.2$ 


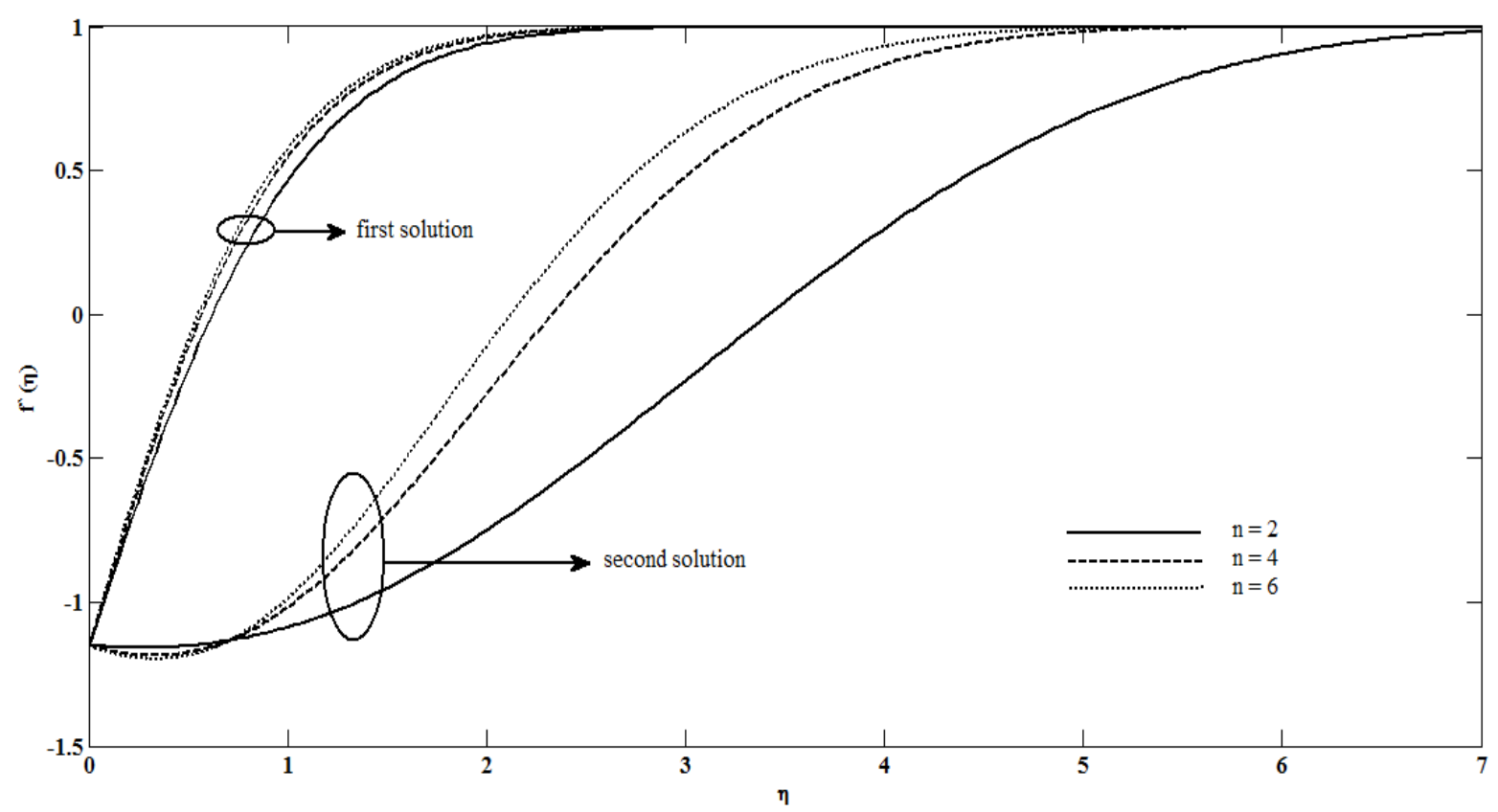

Fig. 11. Velocity profiles for different values of $n$ for Cu-water, $\varphi=0.2, \varepsilon=-1.15, M=0.2$ and $\operatorname{Pr}=6.2$

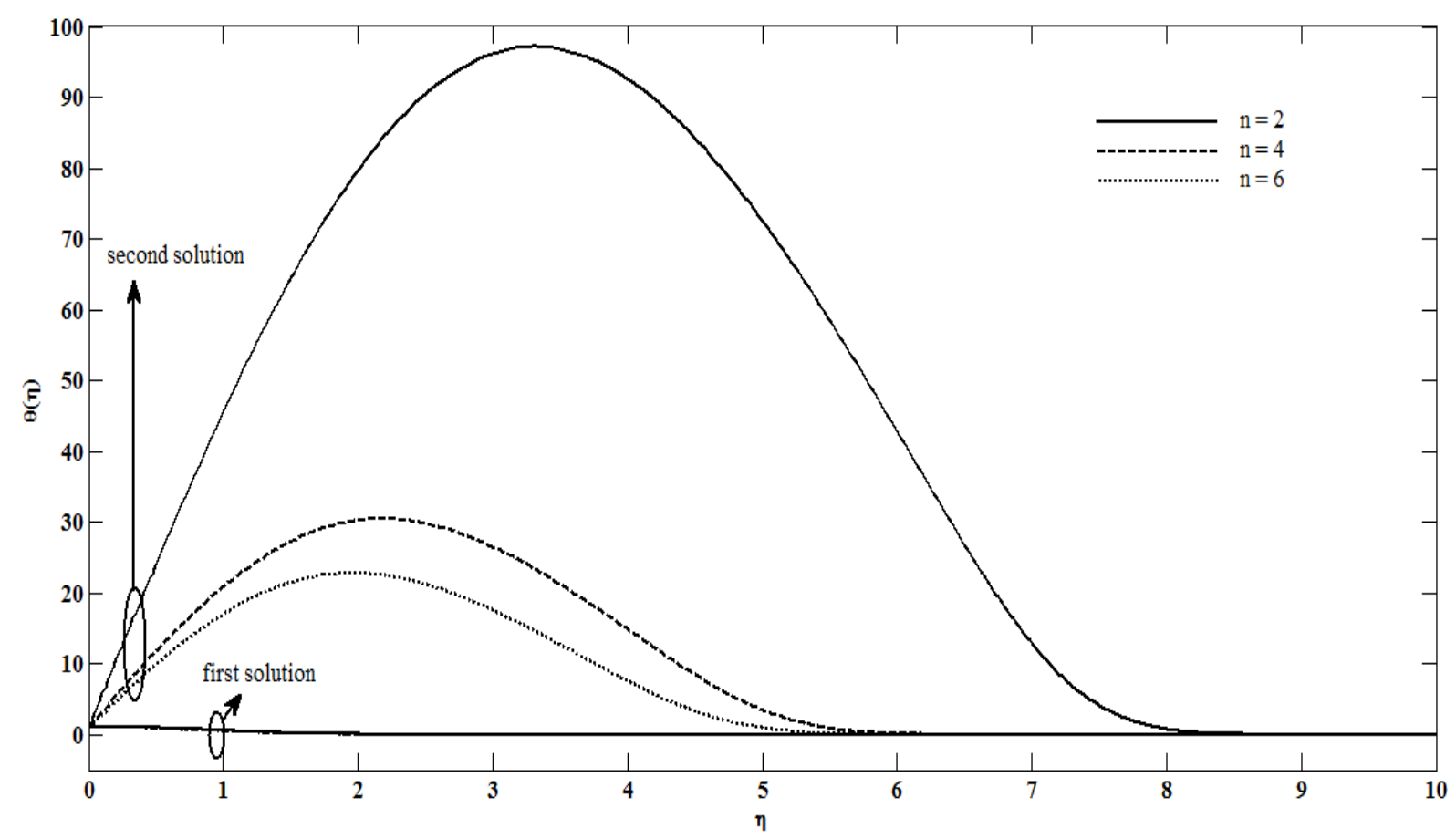

Fig. 12. Temperature profiles for different values of $n$ for Cu-water, $\varphi=0.2, \varepsilon=-1.15, M=0.2 \$$ and $\operatorname{Pr}=6.2$

\section{Conclusions}

We have numerically analyzed in a nanofluid how the parameter $M$ impacts the flow of stagnation point past a nonlinear sheet of stretching/shrinking. The analysis of the influence of the $\varphi$ and the heat transfer features of $\mathrm{Cu}$-water was numerically resolved with $\operatorname{Pr}=6.2$. In this study, it reveals that with the increase of the MHD, the solutions range is widespread. And with the increase in 
magnetohydrodynamics, the range of solutions is expanded widely. As the factor of $M$ increases, the skin friction and heat transfer also do increase.

\section{Acknowledgement}

The authors gratefully appreciate the financial support given in the form of a fundamental research grant scheme (FRGS/1/2018/STG06/UPM/02/4/5540155). Lastly, for all the reviewers, a big thank you for honest feedback and suggestions.

\section{References}

[1] Hiemenz, K. "Dingler's Poly." J 326 (1911): 321.

[2] Crane, L. J. "Z. angew Flow Past a Stretching Plate." Journal of Applied Mathematics and Physics 21, no. 4 (1970): 645-647.

https://doi.org/10.1007/BF01587695

[3] TC, Chiam. "Stagnation-point flow towards a stretching plate." Journal of the physical society of Japan 63, no. 6 (1994): 2443-2444. https://doi.org/10.1143/JPSJ.63.2443

[4] Miklavčič, M., and C. Wang. "Viscous flow due to a shrinking sheet." Quarterly of Applied Mathematics 64, no. 2 (2006): 283-290.

https://doi.org/10.1090/S0033-569X-06-01002-5

[5] Mahapatra, T. Ray, and A. S. Gupta. "Heat transfer in stagnation-point flow towards a stretching sheet." Heat and Mass transfer 38, no. 6 (2002): 517-521.

https://doi.org/10.1007/s002310100215

[6] Mahapatra, Tapas R., and Anadi S. Gupta. "Stagnation-point flow towards a stretching surface." The Canadian Journal of Chemical Engineering 81, no. 2 (2003): 258-263.

https://doi.org/10.1002/cjce.5450810210

[7] Wang, C. Y. "Stagnation flow towards a shrinking sheet." International Journal of Non-Linear Mechanics 43, no. 5 (2008): 377-382. https://doi.org/10.1016/j.ijnonlinmec.2007.12.021

[8] Magyari, E., and B. Keller. "Heat and mass transfer in the boundary layers on an exponentially stretching continuous surface." Journal of Physics D: Applied Physics 32, no. 5 (1999): 577. https://doi.org/10.1088/0022-3727/32/5/012

[9] Rohni, Azizah Mohd, Syakila Ahmad, and loan Pop. "Flow and heat transfer at a stagnation-point over an exponentially shrinking vertical sheet with suction." International journal of thermal sciences 75 (2014): 164-170. https://doi.org/10.1016/j.ijthermalsci.2013.08.005

[10] Mansur, Syahira, Anuar Ishak, and Ioan Pop. "Stagnation-point flow towards a stretching/shrinking sheet in a nanofluid using Buongiorno's model." Proceedings of the Institution of Mechanical Engineers, Part E: Journal of Process Mechanical Engineering 231, no. 2 (2017): 172-180. https://doi.org/10.1177/0954408915585047

[11] Jat, R. N., and S. Chaudhari. "Magnetohydrodynamics boundary layer flow near the stagnation point of a stretching sheet." Nuovo Cimento della Societa Italiana di Fisica. B, General Physics, Relativity, Astronomy and Mathematical Physics and Methods 123, no. 5 (2008): 555-566.

[12] Gretton, Arthur, Kenji Fukumizu, and Bharath K. Sriperumbudur. "Discussion of: Brownian distance covariance." The annals of applied statistics 3, no. 4 (2009): 1285-129. https://doi.org/10.1214/09-AOAS312E

[13] Aman, Fazlina, Anuar Ishak, and Ioan Pop. "Magnetohydrodynamic stagnation-point flow towards a stretching/shrinking sheet with slip effects." International Communications in Heat and Mass Transfer 47 (2013): 68-72. https://doi.org/10.1016/j.icheatmasstransfer.2013.06.005

[14] Vajravelu, K. "Viscous flow over a nonlinearly stretching sheet." Applied mathematics and computation 124, no. 3 (2001): 281-288. https://doi.org/10.1016/S0096-3003(00)00062-X

[15] Bachok, Norfifah, and Anuar Ishak. "Similarity solutions for the stagnation-point flow and heat transfer over a nonlinearly stretching/shrinking sheet." Sains Malaysiana 40, no. 11 (2011): 1297-1300.

[16] Jat, R. N., Abhishek Neemawat, and Dinesh Rajotia. "MHD boundary layer flow and heat transfer over a continuously moving flat plate." International Journal of Statistiika and Mathematika 3 (2012):102-108 
[17] Rana, P., and R. Bhargava. "1.(2012), Flow and heat transfer of a nanofluid over a nonlinear stretching sheet: A numerical study." Communication in Nonlinear Science and Numerical Simulation 17: 212-226.

https://doi.org/10.1016/i.cnsns.2011.05.009

[18] Matin, Meisam Habibi, Mohammad Reza Heirani Nobari, and Pouyan Jahangiri. "Entropy analysis in mixed convection MHD flow of nanofluid over a non-linear stretching sheet." Journal of Thermal Science and Technology 7, no. 1 (2012): 104-119. https://doi.org/10.1299/itst.7.104

[19] Tiwari, Raj Kamal, and Manab Kumar Das. "Heat transfer augmentation in a two-sided lid-driven differentially heated square cavity utilizing nanofluids." International Journal of heat and Mass transfer 50, no. 9-10 (2007): 2002-2018.

https://doi.org/10.1016/j.ijheatmasstransfer.2006.09.034

[20] Oztop, Hakan F., and Eiyad Abu-Nada. "Numerical study of natural convection in partially heated rectangular enclosures filled with nanofluids." International journal of heat and fluid flow 29, no. 5 (2008): 1326-1336. https://doi.org/10.1016/j.ijheatfluidflow.2008.04.009

[21] Milovanov, Valery Ivanovich, Dmitry Alexandrovich Balashov, Valery Ivanovich Milovanov, and Dmitry Alexandrovich Balashov. "Experimental study of a liquid-steam ejector with a conical mixing chamber." Chemical Physics 20, no. 4 (1952): 571-581. https://doi.org/10.1063/1.1700493

[22] Rahman, A. N. H., N. Bachok, and H. Rosali. "Numerical solutions of MHD stagnation-point flow over an exponentially stretching/shrinking sheet in a nanofluid." In Journal of Physics: Conference Series, vol. 1366, no. 1, p. 012012. IOP Publishing, 2019. 